\title{
Enhanced Tensile Strength and Plasticity of Zr-Cu-Al Bulk Glassy Alloys at Cryogenic Temperatures
}

\author{
Asahi Kawashima ${ }^{1}$, Yoshihiko Yokoyama ${ }^{1}$, Ichiro Seki ${ }^{1}$, Hiroaki Kurishita ${ }^{2}$, \\ Mikio Fukuhara $^{1}$, Hisamichi Kimura ${ }^{1}$ and Akihisa Inoue ${ }^{1}$ \\ ${ }^{1}$ Institute for Materials Research, Tohoku University, Sendai 980-8577, Japan \\ ${ }^{2}$ International Research Center for Nuclear Materials Science, Institute for Materials Research, \\ Tohoku University, Oarai, Ibaraki 311-1313, Japan
}

No data are available about mechanical behavior of bulk glassy alloys (BGAs) in tension at cryogenic temperatures. In this study, we investigated the effect of temperature on the mechanical behavior of ternary eutectic and hypoeutectic $\mathrm{Zr}-\mathrm{Cu}-\mathrm{Al} \mathrm{BGAs}$ fabricated by an arc tilt casting method. Tensile tests were performed for the BGA plates with gauge dimensions of $5 \mathrm{~mm}$ in length, $1.2 \mathrm{~mm}$ in width and $0.5 \mathrm{~mm}$ in thickness at temperatures of 295,223, 173 and $77 \mathrm{~K}$, at an initial strain rate of $5 \times 10^{-4} \mathrm{~s}^{-1}$. Measurements of elastic parameters were also made at temperatures from 97 to $342 \mathrm{~K}$ by an ultrasonic pulse method. It is found that the tensile strength and elongation for both BGAs increase with decreasing testing temperature, which is reported for the first time under a tensile condition. At cryogenic temperatures, the tensile elongation of the hypoeutectic $\mathrm{Zr}_{59} \mathrm{Cu}_{31} \mathrm{Al}_{10} \mathrm{BGA}$ tends to be higher than that of the eutectic $\mathrm{Zr}_{50} \mathrm{Cu}_{40} \mathrm{Al}_{10} \mathrm{BGA}$, although the difference is small. Multiple shear bands are observed on the side surface deformed at lower temperatures. The Young's and shear moduli, and Debye temperature monotonically increase with decreasing temperature. This indicates that the BGA becomes rigid and the effective atomic distance decreases at cryogenic temperatures, leading to the increase of the tensile strength at cryogenic temperatures. [doi:10.2320/matertrans.M2009186]

(Received May 26, 2009; Accepted September 10, 2009; Published October 25, 2009)

Keywords: $\mathrm{Zr}_{50} \mathrm{Cu}_{40} \mathrm{Al}_{10}, \mathrm{Zr}_{59} \mathrm{Cu}_{31} \mathrm{Al} l_{10}$, bulk glassy alloy, cryogenic temperature, temperature dependence, tensile strength, plastic strain

\section{Introduction}

Recently, bulk glassy alloys (BGAs) have received great attention as a new class of structural materials because of their unique physical, mechanical and chemical properties. ${ }^{1-5)}$ These unique properties are applicable to industrial materials. ${ }^{6,7)}$ The mechanical behavior of BGAs at room temperature is quite different from that of crystalline alloys. Most of the BGAs under compression show some plasticity before failure at room temperature, while under tension, they display nearly zero tensile elongation. Although numerous efforts have been directed toward improving the ductility of BGAs or bulk glassy alloy matrix composites (BGACs) at room temperature, ${ }^{8-13)}$ little is known about mechanical properties of BGAs and BGACs at cryogenic temperatures.

It is very important to study the mechanical properties of BGA at cryogenic temperatures due to a wider range of applications, such as space exploration, liquefied gas storage. ${ }^{14)}$ But very limited data are available for the mechanical behavior under a compressive loading condition at cryogenic temperatures and the literature is reported only for Zr-based BGAs. ${ }^{14-16)}$ Consequently, we performed compression tests at cryogenic temperatures and at various strain rates using $\mathrm{Cu}_{45} \mathrm{Zr}_{45} \mathrm{Al}_{5} \mathrm{Ag}_{5}, \mathrm{Zr}_{55} \mathrm{Al}_{10} \mathrm{Ni}_{5} \mathrm{Cu}_{30}$ and $\mathrm{Ni}_{60} \mathrm{Pd}_{20} \mathrm{P}_{17} \mathrm{~B}_{3}$ BGA samples. ${ }^{17-19)}$ It was found that the compressive maximum strength and plastic strain prior to failure are higher at cryogenic temperatures than at ambient temperature. Recently, Huang et al. ${ }^{20)}$ reported similar results in compression tests for a $\mathrm{Ti}_{40} \mathrm{Zr}_{25} \mathrm{Ni}_{3} \mathrm{Cu}_{12} \mathrm{Be}_{20}$ BGA. However, no data are available on mechanical behavior under tensile loading for BGAs at cryogenic temperatures.

Very recently, Yokoyama et al. ${ }^{21,22)}$ found that, among ternary $\mathrm{Zr}-\mathrm{Cu}-\mathrm{Al}$ BGAs, hypoeutectic $\mathrm{Zr}_{60} \mathrm{Cu}_{30} \mathrm{Al}_{10}$ BGA exhibits no degradation of ductility and toughness even after complete structural relaxation, although structural relaxation is usually accompanied by severe embrittlement. They also presented that the fatigue behavior of the hypoeutectic BGA remains unchanged even after complete structural relaxation. Furthermore, Yoshida et al. ${ }^{23)}$ reported that the hypoeutectic BGA shows many longer shear bands and higher fracture toughness of $112 \mathrm{MPa} \cdot \mathrm{m}^{1 / 2}$ than a eutectic $\mathrm{Zr}_{50} \mathrm{Cu}_{40} \mathrm{Al}_{10}$ BGA. It is thus expected that the hypoeutectic BGA possesses both high strength and ductility even in tensile tests at cryogenic temperatures.

In this work, the mechanical behavior under a tensile loading condition for the eutectic $\mathrm{Zr}_{50} \mathrm{Cu}_{40} \mathrm{Al}_{10}$ and hypoeutectic $\mathrm{Zr}_{59} \mathrm{Cu}_{31} \mathrm{Al}_{10}$ BGAs is investigated at room and cryogenic temperatures. We also tried to measure the elastic parameters at various temperatures for a better understanding of the mechanical behavior.

\section{Experimental Procedure}

The alloy compositions of the samples were ternary eutectic $\mathrm{Zr}_{50} \mathrm{Cu}_{40} \mathrm{Al}_{10}$ and hypoeutectic $\mathrm{Zr}_{59} \mathrm{Cu}_{31} \mathrm{Al}_{10}$ (at\%). Master alloy ingots were prepared by arc melting a mixture of pure $\mathrm{Cu}, \mathrm{Zr}$ and $\mathrm{Al}$ metals in a purified argon atmosphere. To minimize oxygen concentration during the samples production, we used a special $\mathrm{Zr}$ crystal rod that contained less than 0.05 at $\%$ percent of oxygen. BGA rods of $6 \mathrm{~mm}$ in diameter and rectangular rods with approximate dimensions of $5 \times$ $10 \times 50 \mathrm{~mm}$ were prepared by an arc tilt cast method, ${ }^{24)}$ which features the elimination of crystalline inclusions in BGAs. Tensile specimens were machined from the rectangular rods in which the axis of the specimen lies in the casting direction. The gauge dimensions of those specimens were $5 \mathrm{~mm}$ in length, $1.2 \mathrm{~mm}$ in width, $0.5 \mathrm{~mm}$ in thickness and $1.7 \mathrm{~mm}$ in shoulder radius, as illustrated in Fig. 1. 


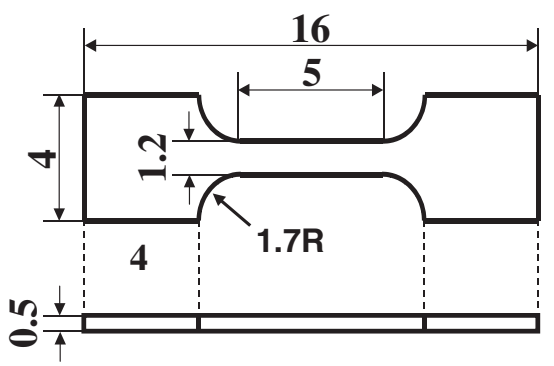

Fig. 1 Dimensions and geometry of tensile test specimen.

In order to investigate the temperature dependence of the mechanical properties, uniaxial tensile tests were performed at $295,223,173$ and $77 \mathrm{~K}$ using a servo-hydraulic testing machine (Shimadzu Servopulser of 50-kN capacity equipped with a $5-\mathrm{kN}$ shear type load cell). The specimens were cooled to the test temperature between $77 \mathrm{~K}$ and room temperature by immersing in a cooling mixture of liquid nitrogen with ethanol during testing. Prior to the tensile tests, the surface of each specimen was mechanically polished to a mirror finish in order to minimize the data variability in the tests. The tensile tests for 5-8 specimens at 295 and $77 \mathrm{~K}$, and 2-3 specimens at 223 and $173 \mathrm{~K}$ were conducted. The fully glassy structure of the as-cast materials was previously confirmed by X-ray diffraction (XRD), differential scanning calorimetry (DSC) and high-resolution transmission electron microscopy (HRTEM). ${ }^{21,22)}$

For a better understanding of the mechanical behavior at cryogenic temperatures, we measured the elastic parameters, such as Young's, shear, and bulk moduli and the Lamé parameter, and elastic Debye temperature as a function of temperature by an ultrasonic pulse method. ${ }^{25)}$ The BGA specimens were in the form of a rod $(7 \mathrm{~mm}$ in length and $5.5 \mathrm{~mm}$ in diameter) and fastened to a stainless steel waveguide with threads of $1.5 \mathrm{~mm}$ pitch, using a domed cap nut of copper. We used a longitudinal wave generating piezoelectric transducer with $7 \mathrm{MHz}$ frequency as the optimum frequency. The elastic parameters were calculated from both longitudinal and transverse wave velocities measured at temperatures from 97 to $342 \mathrm{~K}$ at a heating rate of $0.03 \mathrm{~K} / \mathrm{s}$ in vacuum. The experimental procedure is described elsewhere. ${ }^{26)}$ The value of the Young's modulus at $77 \mathrm{~K}$ was estimated by extrapolation of the modulus-temperature curve. For the calculation of the Debye temperature, ${ }^{27)}$ we used 3.45 as the number of degrees of freedom and $1.103 \times 10^{-27} \mathrm{~m}^{3}$ as the average atomic volume. ${ }^{28)}$ After failure, the side and fracture surfaces were examined by scanning electron microscopy (FE-SEM, Hitachi S-4800).

\section{Results and Discussion}

Figure 2 shows typical stress-strain curves of hypoeutectic $\mathrm{Zr}_{59} \mathrm{Cu}_{31} \mathrm{Al}_{10}$ BGA plates obtained by tensile tests at 295 and $77 \mathrm{~K}$ and at an initial strain rate of $5 \times 10^{-4} \mathrm{~s}^{-1}$. The slopes of the stress-strain curves were calibrated by the Young's modulus obtained by an ultrasonic pulse method. ${ }^{22)}$ The values of Young's modulus for the $\mathrm{Zr}_{59} \mathrm{Cu}_{31} \mathrm{Al}_{10} \mathrm{BGA}$ at 295 and $77 \mathrm{~K}$ were 81 and $91 \mathrm{GPa}$, respectively. The plastic strain $\left(\varepsilon_{\mathrm{p}}\right)$ was estimated from the strain of deviation point of linear region in stress-strain curve to that of final fracture. At $295 \mathrm{~K}$, the specimen shows initial elastic strain, followed by final fracture with significantly small plastic strain that is usually observed for the monolithic $\mathrm{Zr}-\mathrm{Cu}-\mathrm{Al} \mathrm{BGAs}$ at room temperature. There is no clear yielding in the stress-strain curve. On the other hand, at $77 \mathrm{~K}$, the tensile strength $\left(\sigma_{\mathrm{t}}\right)$ is higher than that at $295 \mathrm{~K}$, and more interestingly, the specimen exhibits clear yielding, followed by a certain amount of plastic strain before fracture (Fig. 2(b)); i.e., $\sigma_{\mathrm{t}}$ and $\varepsilon_{\mathrm{p}}$ are $1666 \mathrm{MPa}$ and $0.03 \%$, respectively at $295 \mathrm{~K}$, $1895 \mathrm{MPa}$ and $0.36 \%$, respectively at $77 \mathrm{~K}$. To our knowledge, this is the first evidence of enhanced strength and plastic strain under a tensile loading condition at cryogenic temperatures. Enhanced tensile strength and plastic strain to failure were also observed in the eutectic $\mathrm{Zr}_{50} \mathrm{Cu}_{40} \mathrm{Al}_{10}$ BGA at cryogenic temperatures. Figure 3 shows nominal
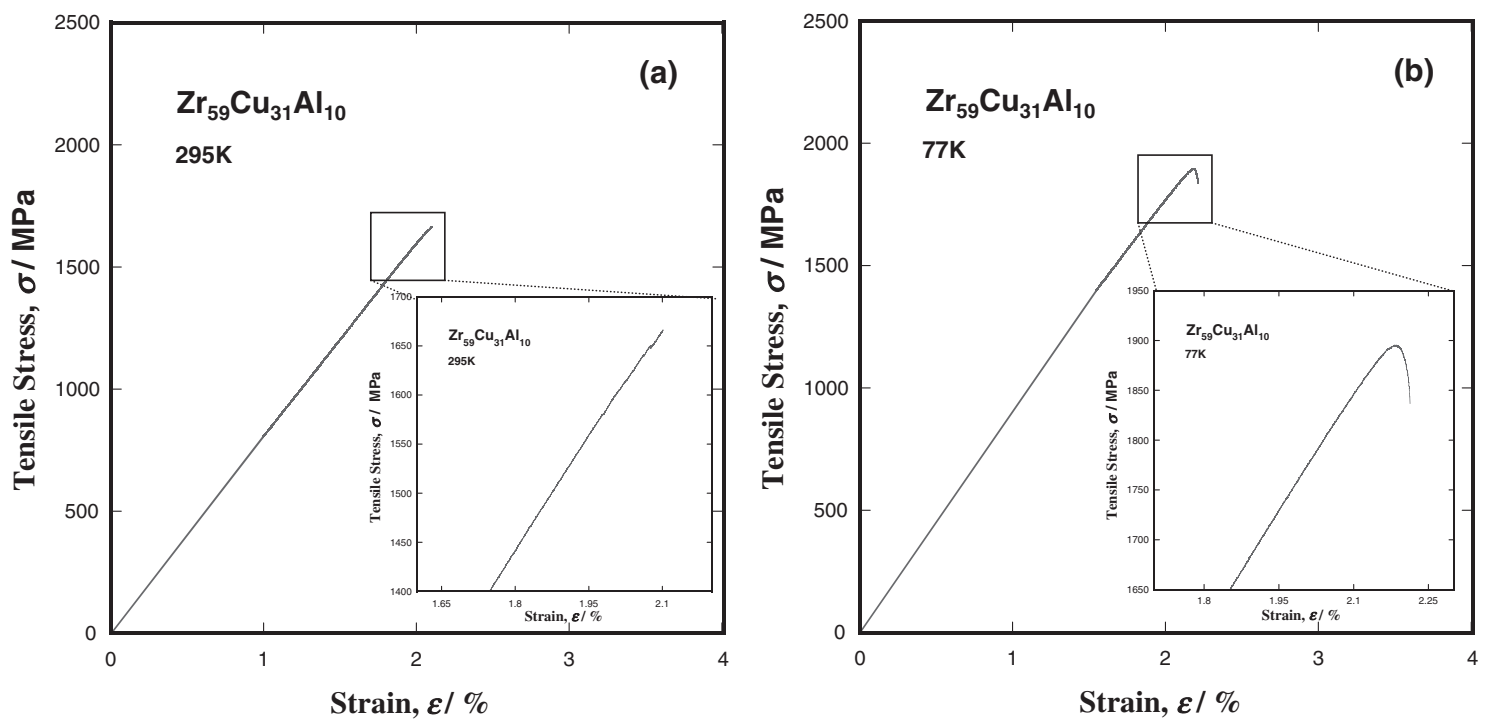

Fig. 2 Nominal stress-strain curves of hypoeutectic $\mathrm{Zr}_{59} \mathrm{Cu}_{31} \mathrm{Al}_{10}$ BGA plates obtained by tensile tests at 295 and $77 \mathrm{~K}$ and at an initial strain rate of $5 \times 10^{-4} \mathrm{~s}^{-1}$. 

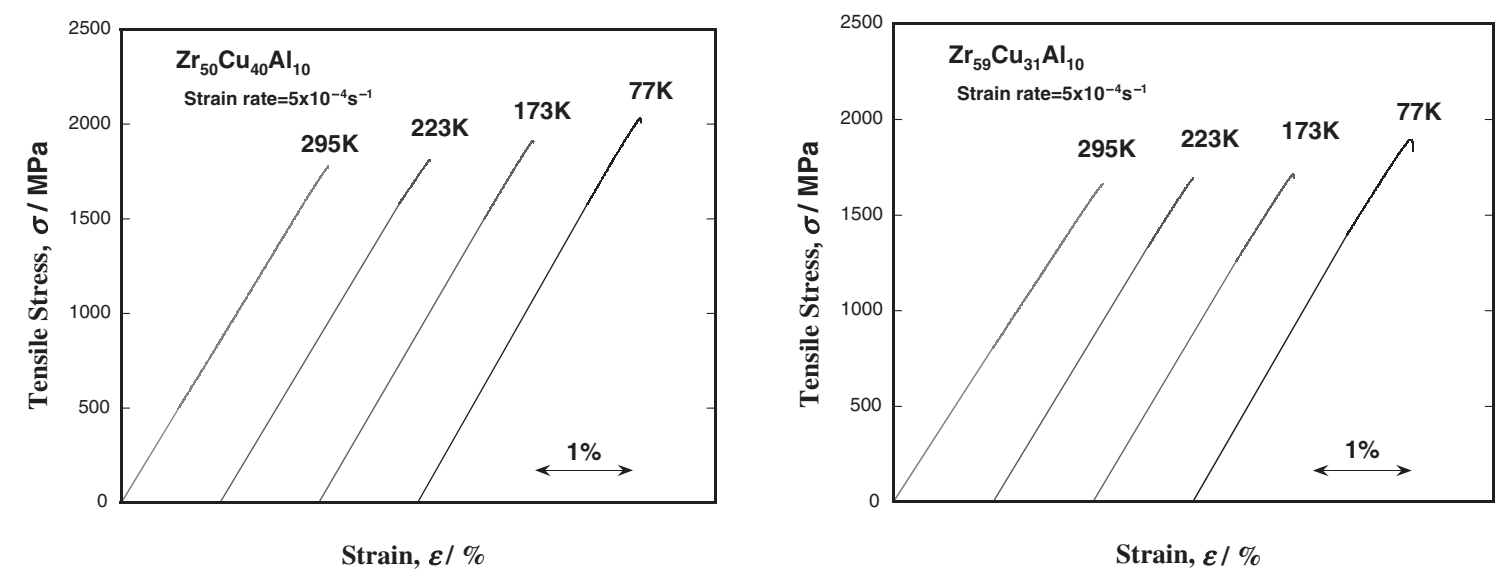

Fig. 3 Nominal tensile stress-strain curves of eutectic $\mathrm{Zr}_{50} \mathrm{Cu}_{40} \mathrm{Al}_{10}$ and hypoeutectic $\mathrm{Zr}_{59} \mathrm{Cu}_{31} \mathrm{Al}_{10} \mathrm{BGA}$ plates at 295 , 223, 173 and $77 \mathrm{~K}$ and at an initial strain rate of $5 \times 10^{-4} \mathrm{~s}^{-1}$.
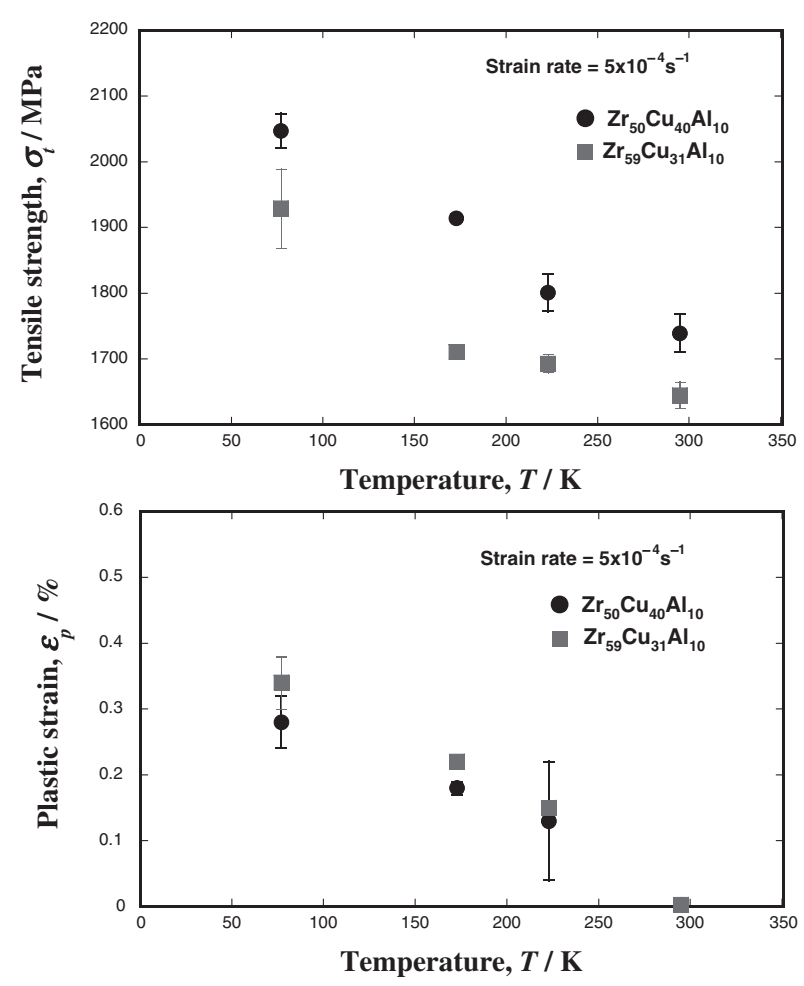

Fig. 4 Temperature dependence of the tensile strength and plastic strain of the eutectic $\mathrm{Zr}_{50} \mathrm{Cu}_{40} \mathrm{Al}_{10}$ and hypoeutectic $\mathrm{Zr}_{59} \mathrm{Cu}_{31} \mathrm{Al}_{10}$ BGA plates measured at a strain rate of $5 \times 10^{-4} \mathrm{~s}^{-1}$.

tensile stress-strain curves of eutectic $\mathrm{Zr}_{50} \mathrm{Cu}_{40} \mathrm{Al}_{10}$ and hypoeutectic $\mathrm{Zr}_{59} \mathrm{Cu}_{31} \mathrm{Al}_{10}$ BGA plates tested at 295, 223, 173 and $77 \mathrm{~K}$ and at an initial strain rate of $5 \times 10^{-4} \mathrm{~s}^{-1}$. For both BGAs, the tensile strength and plastic strain significantly increase with decreasing testing temperature.

Figure 4 summarizes the temperature dependence of the tensile strength and plastic strain of the two glassy alloy plates measured at a strain rate of $5 \times 10^{-4} \mathrm{~s}^{-1}$. It is clear that the tensile strength and plastic strain for both glassy alloys increase monotonically with decreasing testing temperature. The tensile strength for both glassy alloys at $77 \mathrm{~K}$ is about $18 \%$ higher than that at $295 \mathrm{~K}$. Furthermore, the values of the plastic strain of the $\mathrm{Zr}_{50} \mathrm{Cu}_{40} \mathrm{Al}_{10}$ and $\mathrm{Zr}_{59} \mathrm{Cu}_{31} \mathrm{Al}_{10}$ BGAs at
$77 \mathrm{~K}$ are about 9 and 11 times higher than that at $298 \mathrm{~K}$, respectively. At cryogenic temperatures, the tensile elongation of the hypoeutectic $\mathrm{Zr}_{59} \mathrm{Cu}_{31} \mathrm{Al}_{10} \mathrm{BGA}$ tends to be higher than that of the eutectic $\mathrm{Zr}_{50} \mathrm{Cu}_{40} \mathrm{Al}_{10} \mathrm{BGA}$, although the difference is small. The observed increase in plastic strain under tension at cryogenic temperatures is probably due to a higher degree of metallic bonding nature of the hypoeutectic BGA than that of the eutectic BGA. ${ }^{22}$ )

Figure 5 shows SEM images of the side surfaces of the $\mathrm{Zr}_{59} \mathrm{Cu}_{31} \mathrm{Al}_{10}$ BGA plates fractured at 295 and $77 \mathrm{~K}$. For both temperatures, fracture occurs along a single plane, indicating that one major shear band dominates the final failure, and the fracture plane inclines about $56^{\circ}$ with respect to the tensile axis, which is consistent with those reported in the literature, ${ }^{29,30)}$ where the measurements were conducted at room temperature. Similar results were observed at 223 and $173 \mathrm{~K}$. Figure 6 shows tensile fracture and side surfaces of the $\mathrm{Zr}_{59} \mathrm{Cu}_{31} \mathrm{Al}_{10}$ BGA plates at various temperatures. SEM observations show that the fracture surfaces created at each temperature consist of round radiating cores besides an ordinary vein-like pattern, as shown in Fig. 6(a), (c), (e) and (g). It has been reported in the literature ${ }^{31)}$ that the cores on the fracture surface are produced by the normal tensile stress in the initial stage of fracture and the veins are created by the shear stress during rapid shear propagation, leading to the formation of the combined fracture feature. A solidified droplet-like structure is also observed on the fracture surfaces created at each testing temperature. This result indicates that high temperatures up to at least the glass transition temperature can be reached in the shear bands even at $77 \mathrm{~K}$, accompanied by decrease in viscosity within the shear bands. In general, the viscosity of Zr-based BGAs in the supercooled liquid region increases by approximately one order of magnitude with every temperature decrease by $30 \mathrm{~K}^{32}$ ) Therefore, the extent of the decrease in viscosity at sufficiently low testing temperatures could be smaller than that at room temperature, which resulted in partial inhibition of viscous flow in the shear bands and an increase in the tensile strength at cryogenic temperatures. Similar results were obtained for the $\mathrm{Zr}_{50} \mathrm{Cu}_{40} \mathrm{Al}_{10}$ BGA. Therefore, in the present study, the inclination angle and the fracture feature are essentially independent of testing temperature. A signifi- 


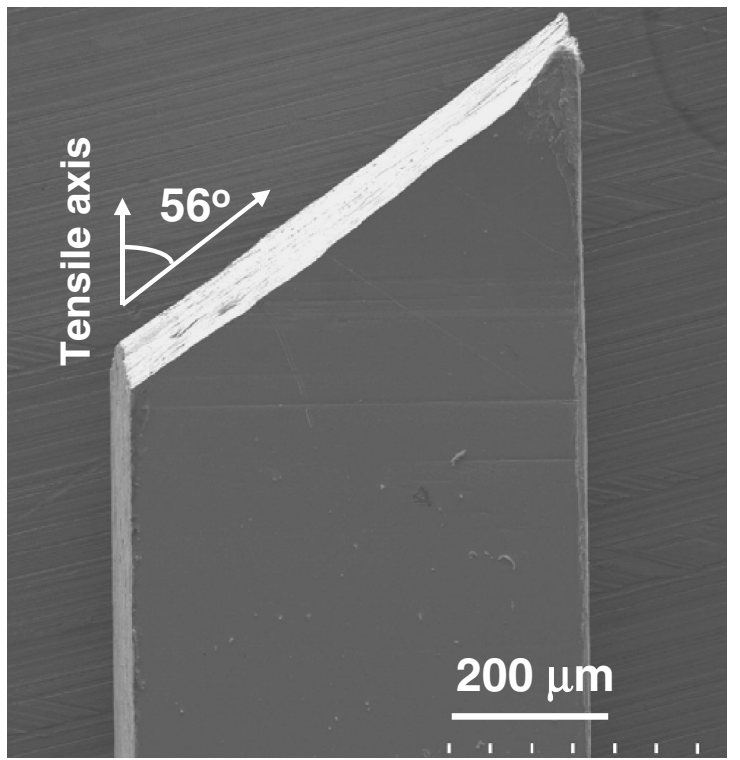

(a) $295 \mathrm{~K}$

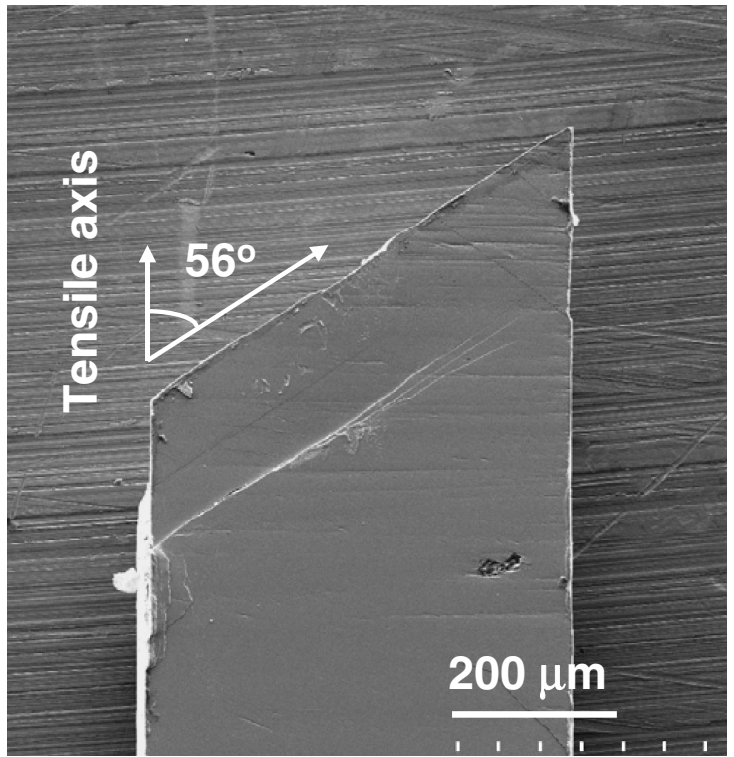

(b) $77 \mathrm{~K}$

Fig. $5 \mathrm{SEM}$ images of the side surfaces of the $\mathrm{Zr}_{59} \mathrm{Cu}_{31} \mathrm{Al}_{10}$ BGA plates around location of fracture created at 295 and $77 \mathrm{~K}$.
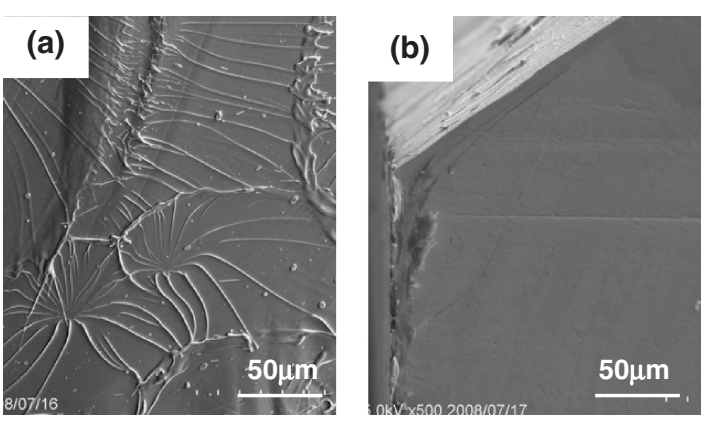

(1) $295 \mathrm{~K}$
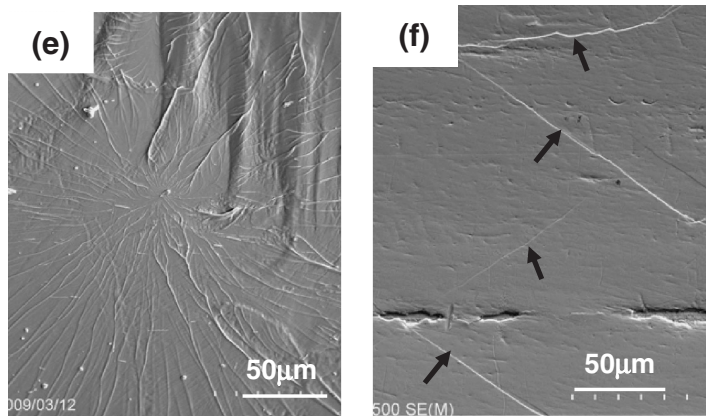

(3) $173 \mathrm{~K}$
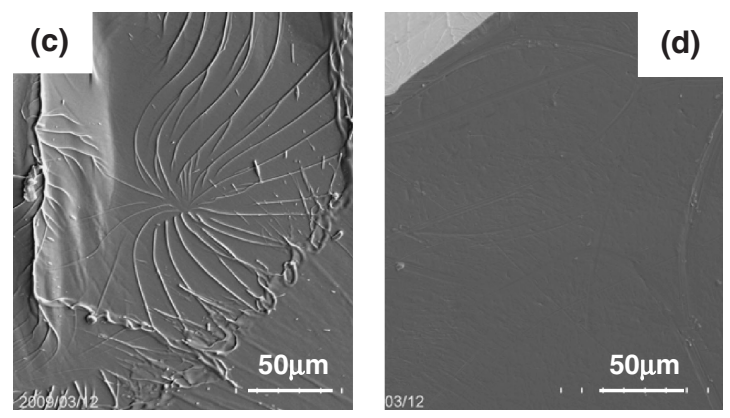

(2) $223 \mathrm{~K}$
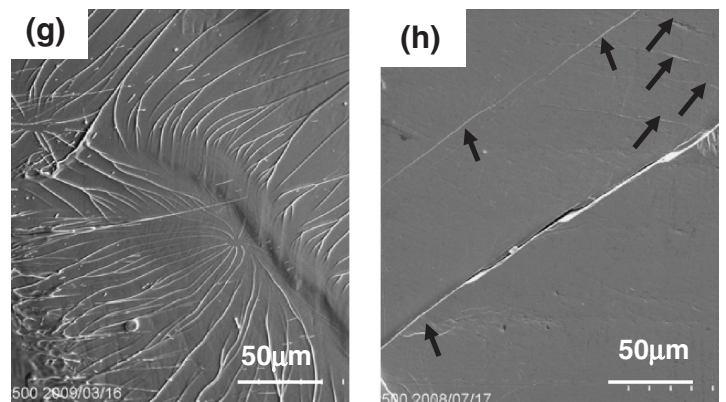

(4) $77 \mathrm{~K}$

Fig. 6 SEM images of the tensile fracture and side surfaces of the $\mathrm{Zr}_{59} \mathrm{Cu}_{31} \mathrm{Al}_{10}$ BGA plates at various temperatures.

cant difference is observed in a shear band structure on the side surface near the fracture surface. At temperatures of 295 and $223 \mathrm{~K}$, almost no shear bands are observed on the side surfaces, as shown in Fig. 6(b) and (d). On the other hand, at 173 and $77 \mathrm{~K}$ many shear bands are observed, as illustrated in Fig. 6(f) and (h). The relative density of shear bands increases with decreasing testing temperature, and thus the ductility increases at cryogenic temperatures.

It is well known that large homogenous plastic deformation of BGAs by viscous flow takes place under the supercooled liquid condition, while BGAs exhibit inhomogeneous plastic deformation by accompanying the generation of highly localized shear bands at temperatures much lower than the glass transition temperature. ${ }^{33)}$ The ductility of glassy alloys is governed by the generation, propagation and accumulation behaviors of shear bands and the dynamic propagation of shear bands is associated with the mobility of free volumes. At cryogenic temperature, it is not certain whether the BGAs become stiff and the mobility of free volumes increases or not. Therefore we measured the elastic parameters of the $\mathrm{Zr}_{59} \mathrm{Cu}_{31} \mathrm{Al}_{10}$ BGA using an ultrasonic pulse method ${ }^{25)}$ as a function of temperature. 


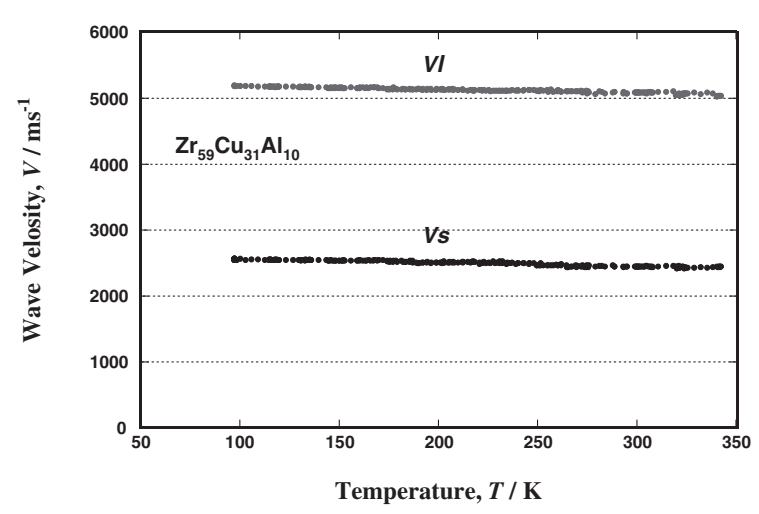

Fig. 7 Change in longitudinal $(V 1)$ and transverse $(V \mathrm{~s})$ wave velocities of the $\mathrm{Zr}_{59} \mathrm{Cu}_{31} \mathrm{Al}_{10}$ BGA specimen with temperature.
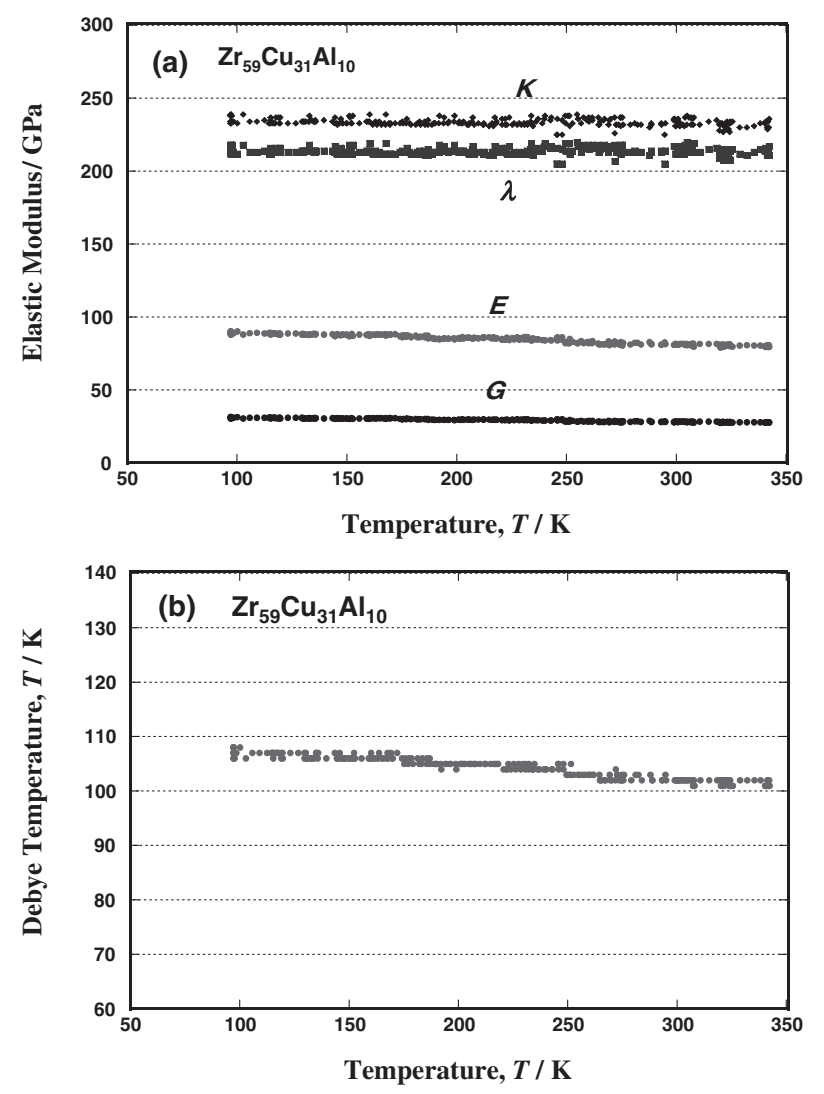

Fig. 8 Temperature dependence of Young's $(E)$, Shear $(G)$ and bulk $(K)$ moduli, lame parameter $(\lambda)$, and Debye temperature of the $\mathrm{Zr}_{59} \mathrm{Cu}_{31} \mathrm{Al}_{10}$ BGA specimen.

Longitudinal and transverse wave velocities and five kinds of the elastic parameters of the $\mathrm{Zr}_{61} \mathrm{Cu}_{31} \mathrm{Al}_{10}$ BGA were measured simultaneously in the range of 97 to $342 \mathrm{~K}$. Figure 7 shows change in longitudinal (Vl) and transverse $(V \mathrm{~s})$ wave velocities with temperature. Both wave velocities increase monotonically with decreasing temperature. This indicates that the bonding strength in the BGA increases with decreasing temperature. Figure 8 shows the Young's $(E)$, shear $(G)$ and bulk $(K)$ moduli, Lamé parameter $(\lambda)$, and Debye temperature for the $\mathrm{Zr}_{59} \mathrm{Cu}_{31} \mathrm{Al}_{10}$ BGA as a function of temperature. The four parameters show a unique order of $K, \lambda, E$ and $G$ over the entire temperature range, which is characteristic of BGAs. ${ }^{34)} E$ and $G$ moduli gradually increase with decreasing testing temperature. This fact indicates that the stiffness of inter-atomic bonds in the BGA increases with decreasing temperature and this causes an increase of the tensile strength at the cryogenic temperatures. Furthermore, the Debye temperature increases monotonically with decreasing temperature, as illustrated in Fig. 8(b). Increase in the Debye temperature, i.e., increase in the maximum frequency allowed, leads to decrease in the effective atomic distance. Thus with decreasing temperature, the effective atomic distance in the BGA decreases. Therefore, increase in the stiffness and decrease in the atomic distance of the BGA at cryogenic temperatures could cause not only increase in the tensile strength but also squeeze of the free volume, so that the mobility of free volumes decreases with decreasing temperature. It is currently accepted that shear band initiation in glassy alloys is related to free volume coalescence. ${ }^{33,35)} \mathrm{At}$ cryogenic temperatures, increased stiffness of the atomic bond makes squeezed free volume coalescence more difficult, since the mobility of the free volume at cryogenic temperature is much lower than that at room temperature. The coalescence of the free volume requires a higher applied load, resulting in the increase of the tensile strength at cryogenic temperatures. The multiple shear bands at lower temperatures are attributed to reduction of the propagation rate of the shear bands and increase in the sites of shear band nucleation, which leads to relatively high ductility of the BGA.

\section{Conclusions}

Tensile tests were conducted for eutectic $\mathrm{Zr}_{50} \mathrm{Cu}_{40} \mathrm{Al}_{10}$ and hypoeutectic $\mathrm{Zr}_{59} \mathrm{Cu}_{31} \mathrm{Al}_{10}$ BGA plates with gauge dimensions of $5 \mathrm{~mm}$ in length, $1.2 \mathrm{~mm}$ in width and $0.5 \mathrm{~mm}$ in thickness at temperatures of $298,223,173,77 \mathrm{~K}$ and at a strain rate of $5 \times 10^{-4} \mathrm{~s}^{-1}$. Measurements of the elastic constants and Debye temperature were also made at temperatures from 97 to $342 \mathrm{~K}$. The main results obtained are as follows.

(1) Tensile strength and elongation for both BGAs increase with decreasing temperature. The tensile strength for both BGAs at $77 \mathrm{~K}$ is about $18 \%$ higher than that at $295 \mathrm{~K}$. The values of the plastic strain of the $\mathrm{Zr}_{50^{-}}$ $\mathrm{Cu}_{40} \mathrm{Al}_{10}$ and $\mathrm{Zr}_{59} \mathrm{Cu}_{31} \mathrm{Al}_{10}$ BGAs at $77 \mathrm{~K}$ are about 9 and 11 times as high as that at $298 \mathrm{~K}$, respectively.

(2) The tensile fracture surfaces consist of some radiating cores and a vein-like pattern at each testing temperature. The side surface deformed at 173 and $77 \mathrm{~K}$ shows multiple shear bands. The multiple shear bands are attributed to reduction of the propagation rate of shear band and increase in the sites of shear band nucleation, which leads to high ductility of the BGAs.

(3) The inclination angle between the fracture surface and tensile axis is about $56^{\circ}$ irrespective of testing temperature.

(4) The Young's and shear moduli, and Debye temperature monotonically increase with decreasing temperature. This result indicates that the BGA becomes rigid and the effective atomic distance decreases at cryogenic temperatures, leading to the increase of the tensile strength at cryogenic temperatures. 


\section{Acknowledgements}

This work was financially supported in part by Grant-inAid for Scientific Research (C) No 20560644 from Japan Society for the Promotion of Science (JSPS) and by Research and Development Project on Advanced Metallic Glasses, Inorganic Materials and Joining Technology from The Ministry of Education, Culture, Sports, Science and Technology (MEXT) of Japan.

\section{REFERENCES}

1) A. Inoue: Mater. Trans. JIM 36 (1995) 866-875.

2) A. L. Greer: Science 267 (1995) 1947-1953.

3) W. L. Johnson: MRS Bull. 24 (1999) 42-56.

4) A. Inoue: Acta Mater. 48 (2000) 279-306.

5) A. Inoue, B. L. Shen and A. Takeuchi: Mater. Trans. 47 (2006) 12751285.

6) H. Kakiuchi, A. Inoue, M. Onuki, Y. Takano and T. Yamaguchi: Mater. Trans. 42 (2001) 678-681.

7) N. Nishiyama, K. Amiya and A. Inoue: Mater. Sci. Eng. A 449-451 (2007) 79-83.

8) A. Inoue, W. Zhang, T. Zhang and K. Kurosaka: Acta Mater. 49 (2001) 2645-2652.

9) L. Q. Xing, Y. Li, K. T. Ramesh, J. Li and T. C. Hufnagel: Phys. Rev. B 64 (2001) 180201.

10) J. Schroers and W. L. Johnson: Phys. Rev. Lett. 93 (2004) 255506.

11) Y. H. Liu, G. Wang, R. J. Wang, D. Q. Zao, M. X. Pan and W. H. Wang: Science 315 (2007) 1385-1388.

12) K. F. Yao and C. Q. Zhang: Appl. Phys. Lett. 90 (2007) 060901.

13) K. Hajlaoui, A. R. Yavari, J. Das and G. Vaughan: J. Alloy. Compd. 434-435 (2007) 6-9.

14) H. Li, K. Tao, C. Fan, P. K. Liaw and H. Choo: Appl. Phys. Lett. 89 (2006) 041921.

15) H. Li, C. Fan, K. Tao, H. Choo and P. K. Liaw: Adv. Mater. 18 (2006) $752-754$
16) E. Tabachnikova, V. Bengus, J. Miskuf, K. Csach, V. Ocelik, W. Johnson and V. Molokanov: Mater. Sci. Forum 343-346 (2000) $197-$ 202.

17) A. Kawashima, T. Okuno, H. Kurishita, W. Zhang, H. Kimura and A. Inoue: Mater. Trans. 48 (2007) 2787-2790.

18) T. Okuno, A. Kawashima, H. Kurishita, W. Zhang, H. Kimura and A. Inoue: Mater. Trans. 49 (2008) 513-517.

19) A. Kawashima, Y. Q. Zeng, M. Fukuhara, H. Kurishita, N. Nishiyama, H. Miki and A. Inoue: Mater. Sci. Eng. A 498 (2008) 475-481.

20) Y. Huang, J. Shen, J. Sun and Z. Zhang: Mater. Sci. Eng. A 498 (2008) 203-207.

21) Y. Yokoyama, T. Yamasaki, M. Nishijima and A. Inoue: Mater. Trans. 48 (2007) 1276-1281.

22) Y. Yokoyama, T. Yamasaki, P. K. Liaw and A. Inoue: Acta Mater. 56 (2008) 6097-6108.

23) N. Yoshida, K. Fujita, Y. Yokoyama, H. Kimura and A. Inoue: J. Japan Inst. Metals 71 (2007) 730-735.

24) Y. Yokoyama, K. Inoue and K. Fukaura: Mater. Trans. 43 (2002) 2316-2319.

25) M. Fukuhara, A. Kawashima, W. Zhang, A. Inoue and F. Yin: J. Appl. Phys. 103 (2008) 013503.

26) M. Fukuhara and A. Sanpei: JPN. J. Appl. Phys. Part 133 (1994) 2890-2893.

27) O. L. Anderson: J. Phys. Chem. Solids 24 (1963) 909-917.

28) M. Fukuhara, X. M. Wang and A. Inoue: Appl. Phys. Lett. 91 (2007) 171908.

29) P. Lowhaphandu, S. L. Montgomery and J. J. Lewandowski: Scr. Mater. 41 (1999) 19-24.

30) K. Yoshimi, H. Kato, J. Saida and A. Inoue: Mater. Trans. 46 (2005) 2870-2874.

31) Z. F. Zhang, J. Eckert and L. Schultz: Acta Mater. 51 (2003) 11671179 .

32) T. Yamasaki, S. Maeda, Y. Yokoyama, D. Okai, T. Fukami, H. M. Kimura and A. Inoue: Intermetallics 14 (2006) 1102-1106.

33) A. S. Argon: Acta Metall. 27 (1979) 47-58.

34) M. Fukuhara, F. Jia, W. Zhang and A. Inoue: Phys. Status Solidi A 203 (2006) 3685-3691.

35) K. M. Flores and R. H. Dauskardt: Acta Mater. 49 (2001) 2527-2537. 